\title{
LIMITES E POSSIBILIDADES DO BLUE \& RED - UM JOGO DE ESTRATÉGIA E ESTATÍSTICA
}

\author{
Fabiano dos Santos Souza \\ Universidade Federal Fluminense, Brasil \\ fabiano_souza@id.uff.br
}

O Ensino de Estatística, no Brasil, é orientado meio dos Parâmetros Curriculares Nacionais com o bloco de Tratamento da Informação para o Ensino Fundamental e Análise de Dados para o Ensino Médio. Esses blocos buscam uma integração de noções básicas de Estatística Descritiva com a Análise Combinatória e Probabilidade, fazendo com que o aluno construa seu conhecimento através de situações do cotidiano. Pesquisas no campo da Educação Estatística (Batanero, Godino, 2005) apontam sobre a necessidade de uma formação em Estatística desde as séries iniciais, para que os alunos da Educação Básica sejam capazes de ler, entender, analisar e interpretar gráficos e tabela. Nesse quadro, (Gal, 2002) ressalta que devemos proporcionar uma cultura estatística aos cidadãos por conta da quantidade de informações que são apresentadas por meio de tabelas e gráficos, informações que muitas vezes não são entendidas. Nessa perspectiva elaboramos uma proposta didático-pedagógica por meio da criação, e do uso de um jogo que desenvolvesse o pensamento estatístico, fixando os conceitos apropriados pelos alunos durante suas aulas, construindo estratégias, e tomadas de decisões a cada jogada, e assim, desenvolvendo seu raciocínio lógico matemático (Borin, 2007, Lopes, 2012).

\section{INTRODUÇÃO}

A Estatística, no Brasil, é um componente curricular na Escola Básica sendo orientada pelos Parâmetros Curriculares Nacionais (PCN) com os blocos Tratamento da Informação para o Ensino Fundamental, e Análise de Dados para o Ensino Médio. Esses blocos buscam integrar noções básicas de Estatística Descritiva com a Análise Combinatória e Probabilidade, fazendo com que o aluno construa seu conhecimento através de situações do cotidiano.

Gal (2002) ressalta que devemos proporcionar uma cultura estatística aos cidadãos por conta da quantidade de informações que são apresentadas por meio de tabelas e gráficos, não sendo bem entendidas em algumas situações. Sobre proporcionar uma cultura estatística, Gal descreve

\begin{abstract}
que se refere aos componentes inter-relacionados: (a) capacidade de interpretar e avaliar criticamente a informação estatística, os argumentos apoiados em dados e os fenômenos estocásticos que as pessoas podem encontrar em diversos contextos, incluindo os meios de comunicação; (b) capacidade para discutir e falar suas opiniões a respeito das informações estatísticas quando são relevantes. (Gal, 2002, p. 2-3).
\end{abstract}

Nesse sentido, para se criar essa cultura estatística, torna-se necessário que haja uma formação Estatística desde as séries iniciais, para que os alunos da Educação Básica sejam capazes de ler, entender, analisar e interpretar gráficos e tabelas conforme sublinham (Batanero, Godino, 2005).

A esses aspectos faz-se necessário acrescentar a importância que o ensino de estatística desenvolva o pensamento estatístico, proporcionando ao estudante a capacidade de utilizar ideias estatísticas e atribuindo um significado à informação desejada (Lopes, Carvalho, 2005).

Pesquisas no campo da Educação Estatística têm indicado sobre a necessidade do desenvolvimento do Pensamento e Letramento Estatístico dos alunos desde a Escola Básica até o Ensino Superior. Coutinho e Souza (2013b) concebem o Letramento Estatístico não apenas a alfabetização, mas o uso correto dos conceitos e procedimentos estatísticos pelo sujeito.

Diante desse cenário emerge a necessidade de buscar alternativas que possam atender essas demandas. Para tanto, elaboramos uma proposta didático-pedagógica por meio da criação e do uso de uma atividade lúdica como o jogo didático, que desenvolvesse o pensamento estatístico fixando os conceitos apropriados pelos alunos durante suas aulas, e ampliasse o raciocínio lógico matemático desse aluno.

In: M.A. Sorto (Ed.), Advances in statistics education: developments, experiences and assessments. Proceedings of the Satellite conference of the International Association for Statistical Education (IASE), July 2015, Rio de Janeiro, Brazil. (C)2015 ISI/IASE iase-web.org/Conference_Proceedings.php 


\section{O JOGO BLUE \& RED}

Os Parâmetros Curriculares Nacionais de Matemática (Brasil, 1998, p. 46) apontam que "os jogos constituem uma forma interessante de propor problemas, pois permitem que estes sejam apresentados de modo atrativo e favorecem a criatividade na elaboração de estratégias de resolução e busca de soluções".

O jogo desenvolvido, denominado Blue \& Red, foi planejado tendo por inspiração o Jogo $3 M s$ (Lopes, Corral, Resende, 2012), criado pelo professor Dr. José Marcos Lopes da Universidade Estadual Paulista - UNESP; A sua criação e validação ocorreu em (2013) por uma equipe constituída por alunos do curso de Licenciatura em Matemática da Universidade Federal Fluminense em Santo Antônio de Pádua, orientada pelo o autor deste artigo, e já foi apresentado por Souza, Tavares e Pereira (2013) no XI ENEM em Curitiba, Brasil, e por Souza (2013) no VII CIBEM em Montevideo no Uruguai.

Borin (2007) conceitua os tipos de jogos com de treinamento e de estratégia. Os Jogos de Treinamento são elaborados com objetivo de auxiliar na fixação de algum conceito a ser estudado. Já nos Jogos de Estratégia, o objetivo principal é proporcionar o desenvolvimento do raciocínio lógico do aluno. Assim, de acordo com a classificação de Borin, o Jogo Blue \& Red é considerado como sendo de treinamento e de estratégia, pois propicia a fixação dos conceitos das medidas de tendência central e dispersão evitando a mera memorização; além de propiciar o raciocínio dedutivo, indutivo e lógico; onde cada jogador efetua suas escolhas e tomadas de decisões, obrigando-os em cada rodada a elaborar e a reelaborar suas hipóteses.

A proposta didático-pedagógica do Jogo Blue \& Red apresenta os seguintes objetivos: (i) fixar os conceitos das medidas de tendência central (média, moda, mediana); (ii) fixar os conceitos de algumas medidas de variabilidade (amplitude, desvio padrão); (iii) fixar os conceitos de outras estatísticas tais como, máximo, mínimo; (iv) desenvolver o raciocínio dedutivo, indutivo e lógico matemático.

Um conjunto do jogo constitui-se por 52 cartas numéricas (figura 1), 18 cartas coringa (figura 1), um tabuleiro (onde serão colocadas as cartas coringa e os descartes; figura 2), um dado de 12 faces (dodecaedro) e um bloco de anotações de cada rodada com os cálculos das estatísticas de cada participante para conferência.

As cartas numéricas são divididas em 26 cartas azuis (blue) com valores positivos e 26 cartas vermelhas (red) com valores negativos. As cartas possuem os seguintes valores: 1, 2, 3, 4, 5, $6,7,8,9,10,15,20,25$. As cartas do jogo podem ser adaptadas por um baralho convencional (representado no quadro 1), onde as cartas cujos naipes são pretos (paus e espadas) seriam as cartas cujos valores são positivos e as cartas cujos naipes são vermelhos (copas e ouros) seriam as cartas cujos valores são negativas.

Quadro 1. Comparação entre as cartas do Jogo Blue \& Red e de um baralho convencional.

\begin{tabular}{|l|l|l|l|l|l|l|l|l|l|l|l|l|l|}
\hline Blue \& Red & 1 & 2 & 3 & 4 & 5 & 6 & 7 & 8 & 9 & 10 & 15 & 20 & 25 \\
\hline Baralho Comum & A & 2 & 3 & 4 & 5 & 6 & 7 & 8 & 9 & 10 & J & Q & K \\
\hline
\end{tabular}
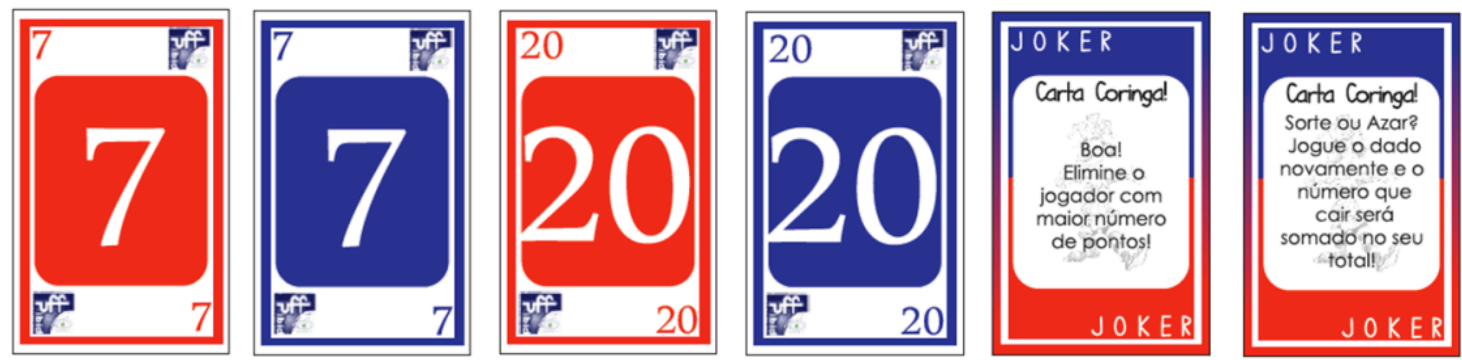

Figura 1. Algumas Cartas do Jogo Blue \& Red 
O dado é utilizado para indicar as estatísticas a serem utilizadas, sendo a representação numérica do dado equivalente aos seguintes procedimentos: 1. Menor Média, 2. Menor Moda, 3. Menor Mediana, 4. Menor Amplitude Total, 5. Mínimo Vermelho (red), 6. Mínimo Azul (blue), 7. Máximo Vermelho (red), 8. Máximo Azul (blue), 9. Menor Desvio padrão, 10. Maior Média, 11. Maior Moda, 12. Maior Mediana.

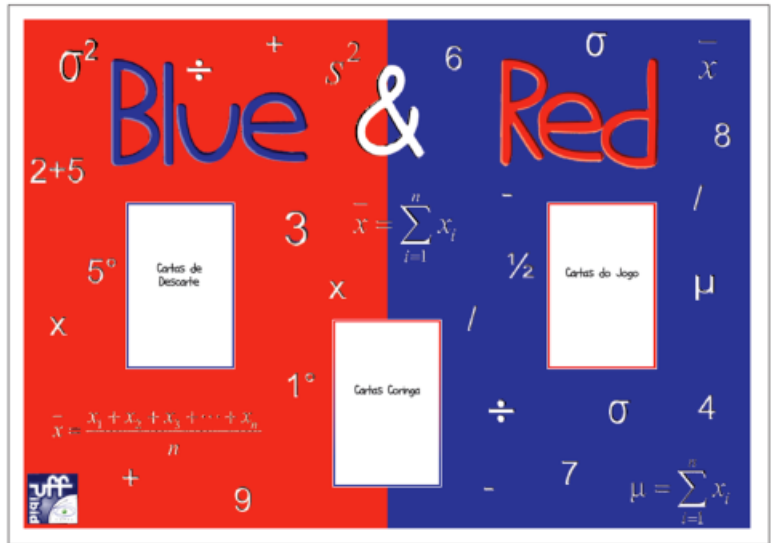

Figura 2. Tabuleiro do Jogo Blue \& Red

Vence o jogo quem obtiver o maior número de pontos após as rodadas utilizando o dado com e mais uma rodada com a carta coringa. As pontuações serão obtidas em função das estatísticas solicitadas por meio das jogadas das rodadas (utilizando o dado) mais a jogada da carta coringa, conforme regra abaixo.

\section{As Regras do Jogo Blue \& Red}

(i) Podem participar do jogo de 2 a 8 pessoas, que recebem, em sentido horário das suas posições, 5 cartas. A quantidade de rodadas é igual ao número de participantes mais uma rodada extra. Nessa rodada extra, cada jogador receberá uma carta coringa e a mesma é jogada na ordem que estiver o jogo. Para iniciar o jogo, cada participante jogará o dado. Inicia-se o jogo aquele jogador que obteve maior valor, e os demais seguem o sentido horário de suas posições. Havendo empate entre participantes no lançamento dos dados, joga-se o mesmo novamente até que saia um vencedor, o qual iniciará o jogo;

(ii) Cada face do dodecaedro tem a sua correspondência com uma estatística conforme descrito anteriormente. Na primeira rodada, ao sair uma das estatísticas, cada jogador na respectiva ordem e no sentido horário deve registrar seus cálculos em sua folha de dados e cálculos. Não pode repetir a estatística durante o jogo, exceto na jogada extra. Após todos jogarem e registrarem seus dados e cálculos é a hora de conferir o cálculo efetuado. Por exemplo, suponhamos que a estatística sorteada seja a maior média, o jogador que acertar o seu cálculo e possuir a maior média, vence a rodada e recebe 3 pontos; no caso de empate, ambos jogadores recebem 1 ponto; Se algum jogador efetuar o cálculo da estatística erradamente, na folha de registro, este deve perder 1 ponto;

(iii) A partir da segunda rodada, cada jogador poderá (opcional) na sua vez descartar uma carta da sua mão e comprar uma carta do monte no tabuleiro, e deverá, portanto, registrar e efetuar o cálculo da nova estatística solicitada na sua folha. Se as cartas do monte terminarem, as cartas de descarte deverão ser embaralhadas, e este será um novo monte de compras;

(iv) Na rodada extra, cada jogador na ordem que estiver o jogo pegará uma carta coringa. Em posse dessa carta coringa, cada jogador na sua vez irá ler em voz alta o que lhe foi solicitado e efetuará os cálculos quando necessário for;

(v) Ganha o jogo aquele jogador que possuir maior número de pontos.

Algumas adaptações do Jogo Blue \& Red podem ser feitas, principalmente na estatística do desvio padrão que não é visto no Ensino Fundamental. 


\section{DISCUSSÃO E RESULTADOS}

Faz-se necessário, inicialmente, tecer algumas considerações acerca do Jogo Blue \& Red, destacando alguns aspectos positivos do jogo: (i) cálculo das medidas de tendência central e dispersão; (ii) tomada de decisão a cada rodada, efetuando estimativas mentais com as cartas do jogo, avaliando o cálculo e os conceitos das estatísticas; (iii) análise de dados com valores discrepantes (positivos e negativos); (iv) a melhor estratégia usada pelo jogador em cada estatística e rodada.

Ainda apoiados em Borin (2007, p. 8) acreditamos que o nosso jogo ao ser utilizado no processo de ensino-aprendizagem tem um papel importante no desenvolvimento de habilidades de raciocínio como organização, atenção, concentração, raciocínio dedutivo, exigidos na escolha de cada jogada; habilidades que compõe o raciocínio lógico, tais como: tentar, observar, analisar, conjecturar, verificar.

Corroborando com o pensamento de Batanero (2005) a qual destaca que devemos proporcionar ferramentas metodológicas para analisar a variabilidade, determinar as relações entre as variáveis, desenvolver situações/estudos com experimentos e melhorar as predições para auxiliar na tomada de decisões em situações de incerteza. Nesse sentido, o jogo Blue \& Red proporciona aos jogadores uma análise da variabilidade das cartas; e por meio da estratégia utilizada por cada jogador, este pode melhorar as suas predições para auxiliar na tomada de decisões em situações de incerteza proporcionadas pelo jogo.

Realizamos um teste da proposta didático-pedagógica junto aos doze bolsistas do Programa Institucional de Bolsa de Iniciação à Docência (PIBID) e mais dois professores supervisores da Educação Básica. Dividimos o grupo em dois e jogamos o Blue \& Red por 5 vezes, pois conforme ressaltam Macedo, Petty e Passos (2007, p. 20) "é importante conhecer os materiais do jogo e promover todo o tipo de situação que possibilite seu conhecimento e a assimilação das regras". Os grupos analisaram após o término de cada partida as jogadas efetuadas e as possibilidades que cada jogador tinha em mãos através dos registros efetuados. Essa experiência inicial com o grupo do PIBID coordenado pelo o autor principal deste trabalho nos proporcionou resultados animadores, trazendo reflexões e discussões importantes sobre o uso de jogos para o Ensino de Estatística. Ademais, percebemos que ao jogarem os participantes apresentaram uma grande motivação, apresentando atitudes positivas frente aos seus processos de aprendizagem. $\mathrm{O}$ jogo proporcionou aos participantes a exercitarem suas habilidades mentais e a buscarem melhores estratégias para vencer.

O jogo também foi aplicado qualitativamente a alunos de duas turmas do nono ano do Ensino Fundamental da Escola Municipal Escola Viva, localizada no município de Santo Antônio de Pádua, interior noroeste do Estado do Rio de Janeiro, nos anos de 2012 e 2013. As experiências nos revelaram o quanto os alunos ficaram motivados com o jogo. Grande parte dos alunos convergiu sobre a necessidade de não apenas efetuar os cálculos das estatísticas, e sim de pensar a cada rodada antes da tomada de decisão. $\mathrm{Na}$ análise se evidencia, também, o fato de que alguns alunos apresentaram dificuldades com as estatísticas (máximo e mínimo vermelho, amplitude). Os alunos em posse das cartas do baralho que são positivas e negativas e a ansiedade em dar a resposta rapidamente deslizaram na hora das respostas com essas estatísticas. Ressaltamos ao final das partidas que antes de escreverem as respostas há uma necessidade de realizarem conjecturas sobre as mesmas, sobre os processos e cálculos realizados. Por outro lado, foi importante para verificarmos que os alunos tinham ainda um pouco de dificuldade com a reta numerada $\mathrm{e}$ operações elementares com os números inteiros.

Outro relato importante, que devemos destacar refere-se às oficinas aplicadas no Dia da Matemática do Laboratório de Educação Matemática (LABEM) da Universidade Federal Fluminense (UFF), na Faculdade de Educação em maio de 2013 para 23 alunos e 7 professores da Educação Básica. E a oficina aplicada em maio de 2014, no Instituto do Noroeste Fluminense de Educação Superior para 21 alunos do primeiro período da licenciatura em Matemática.

É necessário, também, assinalar que no decorrer das oficinas buscamos conforme Macedo, Petty e Passos (2007) instigar os participantes a analisar as suas ações, estratégias, decisões tomadas, pesquisando outras formas de jogar como de buscar variações em suas estratégias. Os resultados observados aos ministrarmos as oficinas foram motivadores. A implementação do jogo nessas oficinas estiveram na perspectiva dos pesquisadores (Macedo, Petty, Passo, 2007). 
Utilizamos a mesma estratégia aplicada com o grupo do PIBID, ou seja, ao final de cada partida fomos aos grupos em busca de discussões, impressões, reflexões que o jogo proporcionou aos participantes, pois conforme sublinham Macedo, Petty, Passos (2007, p. 26), "ao jogar e discutir partidas, muitos conceitos são reavaliados, bem como diferentes aspectos do conhecimento são ampliados e aprofundados". Na perspectiva dos alunos de modo geral gostaram muito da dinâmica do jogo, e da possibilidade de trabalhar com a média, moda e mediana e as medidas de dispersão por meio do jogo. $\mathrm{Na}$ análise dos professores participantes, o grupo destacou como aspecto positivo o jogo trabalhar com números positivos e negativos e com valores discrepantes, onde a variabilidade dos dados de cada jogador foi importante a cada rodada na tomada de decisão.

\section{CONSIDERAÇÕES FINAIS}

Neste artigo nos propomos a apresentar e discutir o uso de jogo Blue \& Red para o Ensino de Estatística, identificando contribuições, reflexões sobre o uso de jogos, limites e possibilidades dessa ferramenta para o desenvolvimento do letramento estatístico.

Acreditamos que, para se concretizar de forma plena a proposta aqui analisada, faz-se necessário romper com um Ensino de Estatística com ênfase no aspecto matemático dos algoritmos dos cálculos das medidas estatísticas para um ensino com o uso de metodologias de jogos, resolução de problemas, Análise Exploratória de Dados que conforme (Coutinho, Souza, 2013a) indicam a coleta de dados de forma contextualizada, é um elemento basilar da construção do letramento estatístico; dando mais ênfase aos conceitos e significados, proporcionando uma aprendizagem conceitual.

Sobre a utilização de jogos, Borin (2007) destaca a possibilidade de diminuir bloqueios que os alunos apresentam em relação ao Ensino de Matemática. Dessa forma, os alunos que jogam apresentam um melhor desempenho e atitudes positivas em seus processos de aprendizagem.

Nesse sentido, defendemos a ideia que o professor pode e deve trabalhar com uma ampla variedade de jogos em sala de aula, "desde que não sejam utilizados somente como fins em si mesmos, mas transformados em material de estudo e ensino (na perspectiva do profissional), bem como em aprendizagem e produção de conhecimento (na perspectiva do aluno)" (Macedo, Petty e Passos, 2007, p. 18).

Cabe assinalar, ainda, para os fins deste trabalho, que é importante desenvolver o pensamento estatístico, o qual permite que os estudantes sejam capazes de utilizar ideias estatísticas e atribuir um significado à informação desejada (Lopes, Coutinho, Almouloud, 2010).

Abordamos, neste trabalho, aspectos relevantes do Jogo Blue \& Red, por considerá-lo uma contribuição bastante significativa para a reflexão sobre a utilização de jogos para o Ensino de Estatística, dadas todas as observações realizadas durante a aplicação deste jogo com alunos, docentes formados e em formação.

\section{REFERÊNCIAS}

Batanero, C., \& Godino, J. D. (2005). Perspectivas de La educación estadística como área de investigación. En R. Luengo (Ed.), Líneas de investigación en Didáctica de lãs Matemáticas Badajoz: Universidad de Extremadura, p. 203-226.

Borin, J. (2007). Jogos e resolução de problemas: uma estratégia para as aulas de matemática. 6. ed. São Paulo: IME-USP.

Brasil. (1998). Secretaria de Educação Fundamental. Parâmetros curriculares nacionais: matemática: ensino de quinta à oitava séries. Brasília: MEC.

Coutinho, C. Q. S., \& Souza, F. S. (2013a). Aprendizagem da Estatística e o uso de ambientes computacionais: uma análise didática de programas para construção de gráficos estatísticos. In: VII Congreso Iberoameticano de Educación Matemática, Montevideo, Uruguai, p.6221-6228.

Coutinho, C. Q. S., \& Souza, F. S. (2013b). Desenvolvimento do letramento estatístico e a leitura e análise de gráficos: uma análise didática sobre a contribuição de ambientes computacionais como R e Geogebra. In Boletim Labem, ano 5, n. 8, p. 8-15, jan/jun, Rio de Janeiro.

Gal, I. (2002). Adult's statistical literacy. Meanings, components, responsibilities. International Statistical Review, 70(1), 1-25. $\quad$ Recuperado de http://www.stat.auckland.ac.nz/ iase/cblumberg/gal.pdf. Consultado 10/01/2013. 
Lopes, C., Coutinho, C., \& Almouloud, S. (2010). Estudos e reflexões em educação estatística., São Paulo: Mercado de Letras.

Lopes, C., \& Carvalho, C. (2005). Literacia Estatística na Educação Básica. In Leituras e escritas na Educação Matemática. p. 77-92, Belo Horizonte: Autêntica.

Lopes, J. M., Corral, R. S., \& Resende, J. S. (2012). O estudo da média, da mediana, e da moda através de um jogo e da resolução de problemas Revista Eletrônica de Educação. UFSCar, (2)6, 250-270, nov, São Carlos, São Paulo.

Macedo, L., Petty, A. L . S., \& Passos, N. C. (2007). Aprender com jogos e situações-problema. [recurso eletrônico]. Porto Alegre: Artmed.

Souza, F. S., Tavares, R. A., \& Pereira, F. A. (2013). Blue \& Red: Um Jogo de Estratégia e Estatística. In Anais do XI ENEM - Encontro Nacional de Educação Matemática, Curitiba.

Souza, F. S. (2013). Blue \& Red: Um Jogo de Estratégia e Estatística. In VII Congreso Iberoameticano de Educación Matemática, p. 8064-8070, Montevideo, Uruguai. 